ORIGINAL ARTICLE

\title{
Diagnostic Accuracy of Hysterosonography in Diagnosis of Uterine Lesions by Taking Hysteroscopy as Gold Standard
}

\author{
FARAH NAZ ${ }^{1}$, ADNAN AHMED ${ }^{2}$, SAMINA SHAIKH ${ }^{3}$, HAFEEZ UR REHMAN ${ }^{4}$, TAHIR BAIG ${ }^{5}$, M. NAUMAN AKRAM ${ }^{6}$ \\ ${ }^{1,3}$ Senior Registrar, Gynae/Obs Liaquat University of Medical and Health Sciences, Jamshoro Pakistan \\ ${ }^{2}$ Associate Professor Radiology, Liaquat University of Medical and Health Sciences, Jamshoro Pakistan \\ ${ }^{4}$ Senior Registrar Radiology, Gajju Khan Medical College, Swabi Pakistan \\ ${ }^{5}$ Assistant Professor Radiology, Rai Medical College, SargodhaPakistan \\ ${ }^{6}$ Assistant Professor Radiology, Sahara Medical College, Narowal Pakistan \\ Corresponding author: Dr Farah Naz, Email: drfarahnaz81@hotmail.com, Cell: +92333 2624217
}

\begin{abstract}
Background and Aim: Evaluation of uterine abnormalities is infertility core partto be assessed in impaired reproduction cases. Uterine abnormalities can be assessed by various radiological imaging modalities such as transvaginal sonography, hysterosalpingography and hysterosonography. The current study aims to evaluate the diagnostic accuracy of hysterosonography in diagnosis of uterine lesions by taking hysteroscopy as gold standard.

Materials and Methods: This observation-based cross-sectional study was carried out on 108 reproductive-age women at the Department of Obstetrics and Gynecology of Liaquat University of Medical and Health Sciences, Jamshoro during the period from January 2020 to June 2020. These women had uterine abnormalities such as recurrent pregnancy loss, abnormal uterine bleeding, infertility, and clinically diagnosed lesions of intrauterine. All individuals underwent hysteroscopy evaluation. Global sensitivity analysis technique was used to calculate the bias-adjusted specificity and sensitivity of hysterosonography. Uterine abnormalities were assessed by hysteroscopy taking it as a gold standard. SPSS version 20 was used for data analysis.

Results:The mean age of the women was $27.3 \pm 5.63$ with age range 20 to 34 years and parity ranged from 0 to 5. Out of 108 patients, $49(45.4 \%)$ had positive findings of abnormal uterine lesions including myomas in 13 (12.3\%), polyps 17 (15.7\%), uterine septum 7 (6.4\%) and intrauterine adhesions 12 (11.1\%). Among all, fortynine (45.4\%) women had infertility, previous cesarean section 20 (19.1\%), recurrent pregnancy loss 18 (16.6\%), and menstrual disorders 21 (19.4\%).Diagnostic accuracy of hysterosonography in terms of specificity, sensitivity, and Positive prediction value (PPV) was $94 \%, 77 \%$, and $74 \%$ for uterine lesions respectively while taking hysteroscopy as a gold standard.

Conclusion: The present study concluded that uterine lesions among reproductive-age women could be easily assessed with higher accuracy of hysterosonography. Based on the specificity and sensitivity of hysteroscopy as a gold standard for hysterosonography is the most reliable, safe and accurate diagnostic technique for uterine lesions.
\end{abstract}

Keywords:Hysterosonography, Uterine lesions

\section{INTRODUCTION}

Impaired reproduction developed with abnormal uterine lesions needs to be assessed [1]. The female pelvis can be easily evaluated with hysterosonography due to its availability and quick performance. However, conflicting studies were found on the accuracy of hysterosonography $[2,3]$. Uterine activities can be evaluated with equivocal findings and invasive investigation with hysterosonography [4]. Diagnostic hysteroscopy was considered as a gold standard for uterine lesions abnormalities.Operative sonohysterography may be suggested by the surgeon provided the diagnosis specificity of it. Diagnostic hysteroscopy may be precluded by less invasive sonohysterography [5]. The investigation method has not been presented as alternate gold standard tests. The prevalence of uterine lesions was found higher in infertile patients. Therapeutic success could be mostly related to abnormal uterine cavity treatment and detection. In such cases, son- hysteroscopy has been an approved diagnostic tool [6].

Fertility problems like excessivemenstrual blood loss in reproductive-age women were diagnosed withhyterosonography. However, for uterine lesions, a detailed examination was not carriedout [8]. Another reliable evaluation techniques are three-dimensional sonohysterographywhich enables uterine contour assessment, focal disease, and adhesions [9]. Three perpendicular plans demonstration can be enabled by giving access to unobtainable sections simultaneously by3dimensional sonohysterography. Additionally, the endometrium on both sides with the inner surface clearly visible can be visualized by saline solution in the distendedcavity [10]. Another study compared the threedimensional hysteroscopy withconventional one but found three-dimensional hysteroscopy economical, lessinvasive, and does not require anesthesia [11]. Another study compared two and three-dimensionalhysteroscopy [12, 13]. Therefore, a detailed study needs to be conducted on the hysteroscopydiagnostic accuracy for uterine lesions abnormalities. The primary aim of the current study was to evaluate the diagnostic accuracy in terms of specificity and sensitivity in the diagnosis of uterine lesions among reproductive age women taking hysteroscopy as a gold standard.

\section{MATERIALS AND METHODS}

This observation-based cross-sectional study was carried out on 108 reproductive-age women at the Department of 
Obstetrics and GynecologyofLiaquat University of Medical and Health Sciences,Jamshoro during the period from January 2020 to June 2020. These women had uterine abnormalities such as recurrent pregnancy loss, abnormal uterine bleeding, infertility, and clinically diagnosed lesions of intrauterine. All individuals underwent hysteroscopy were evaluated.Ethical committee approval was taken and a written consents form was obtained from all the individual prior to conducting the study. The study population was 108 reproductive age women with suspected intrauterine abnormalities, recurrent pregnancy loss, infertility and menstrual disorder. Profuse uterine bleeding or perforation, cervical malignancy, pelvic inflammatory diseases, pregnancy and cervical stenosis were excluded from the study. Global sensitivity analysis technique was used to calculate the bias-adjusted specificity and sensitivity of hysterosonography. Uterine abnormalities were assessed by hysteroscopy taking it as a gold standard. The mean age of the women was $27.3 \pm 5.63$ with age range 20 to 34 years and parity ranged from 0 to 5 . Out of 108 patients, 49 $(45.4 \%)$ had positive findings of abnormal uterine lesions including myomas in $13(12.3 \%)$, polyps $17(15.7 \%)$, uterine septum 7 (6.4\%) and intrauterine adhesions 12 (11.1\%). Among all, forty-nine (45.4\%) women had infertility, previous cesarean section 20 (19.1\%), recurrent pregnancy loss 18 (16.6\%), and menstrual disorders 21 (19.4\%). Diagnostic accuracy of hysterosonography in terms of specificity, sensitivity, and Positive prediction value (PPV) was 94\%, 77\%, and $74 \%$ for uterine lesions respectively while taking hysteroscopy as a gold standard.

Hysterosonography was conducted with 5 to $7 \mathrm{MHz}$ transduceron ultrasound. Lithotomy position was followed for women with an empty bladder. The antiseptic solution was used to clean the cervix and the vaginal speculum was inserted with sterile. Air artifact was mitigated withsaline solution prefilled the catheter inside the uterine cavity beforeinsertion. Foley catheter (8F pediatric) was label-off. Long traumatic forceps was utilized to guidethe catheter into the uterine cavity and inflated balloon with sterile saline solution(1-2 $\mathrm{mL}$ ) was inserted for internal cervical os and stabilization. Then careful withdrawalof speculum and probe insertion was done with vaginal posterior fornix. Catheter with $20 \mathrm{~mL}$ saline solution sterilewas attached to a plastic syringe and inside the uterine cavity, catheter positionwas ascertained. Hysterosography visualized the fluid inside uterine distention. Data analysis was carried out in SPSS version 20. Frequency and percentage for categorical variables such as age, the accuracy of hysteroscopy, and intrauterine lesions were calculated with sensitivity and specificity. A $\mathrm{p}$-value was considered a significant value.

\section{RESULTS}

The mean age of the women was $27.3 \pm 5.63$ with age range 20 to 34 years and parity ranged from 0 to 5 . Out of 108 patients, 49 (45.4\%) had positive findings of abnormal uterine lesions including myomas in 13 (12.3\%), polyps 17 $(15.7 \%)$, uterine septum $7(6.4 \%)$ and intrauterine adhesions 12 (11.1\%). Among all, forty-nine (45.4\%) women had infertility, previous cesarean section 20 (19.1\%), recurrent pregnancy loss 18 (16.6\%), and menstrual disorders $21(19.4 \%)$ as shown in Figure 1.
Diagnostic accuracy of hysterosonography in terms of specificity, sensitivity, and Positive prediction value (PPV) was $94 \%, 77 \%$, and $74 \%$ for uterine lesions respectively while taking hysteroscopy as a gold standard. A total of 108 suspected intrauterine eligible women were included with clinical details shown in Table 1.

Table 1. Clinical data of 108 patients

\begin{tabular}{|l|l|}
\hline Variables & Value $\mathrm{n}(\%)$ \\
\hline Age (mean \pm SD) (years) & $27.3 \pm 5.63$ \\
\hline Parity & 0.96 \\
\hline Previous cesarean section & $20(19.1)$ \\
\hline Infertility & $49(45.4)$ \\
\hline Menstrual disorders & $21(19.4)$. \\
\hline Pregnancy recurrence & $18(16.6)$ \\
\hline
\end{tabular}

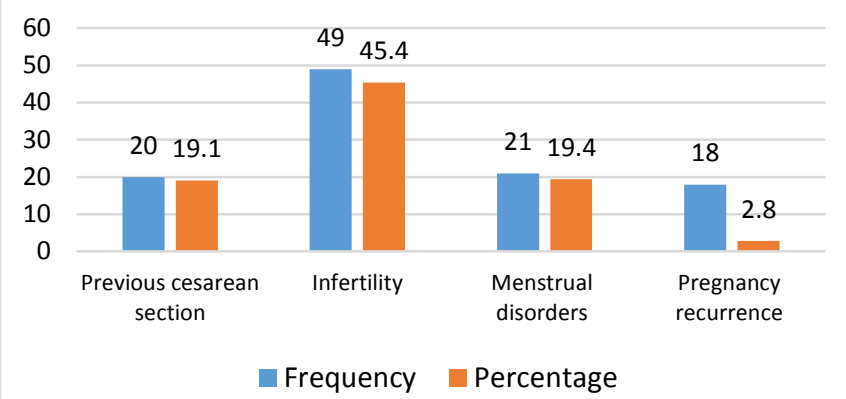

Figure 1. Prevalence of reproductive abnormalities

Table 2. Intrauterine lesions diagnostic parameters

\begin{tabular}{|l|l|}
\hline Parameters & Value (\%) \\
\hline Specificity & 94 \\
\hline Sensitivity & 77 \\
\hline Negative predictive value & 81 \\
\hline Positive predictive value & 74 \\
\hline Overall accuracy & 92 \\
\hline
\end{tabular}

Table 3. Intrauterine Lesionsof positive findings among 49 patients

\begin{tabular}{|l|l|l|}
\hline Intrauterine Lesions & Frequency $\mathrm{n}$ & Percentage \% \\
\hline Myomas & 13 & 12.3 \\
\hline Polyps & 17 & 15.7 \\
\hline Uterine Septum & 7 & 6.4 \\
\hline Intrauterine adhesions & 12 & 11.1 \\
\hline
\end{tabular}

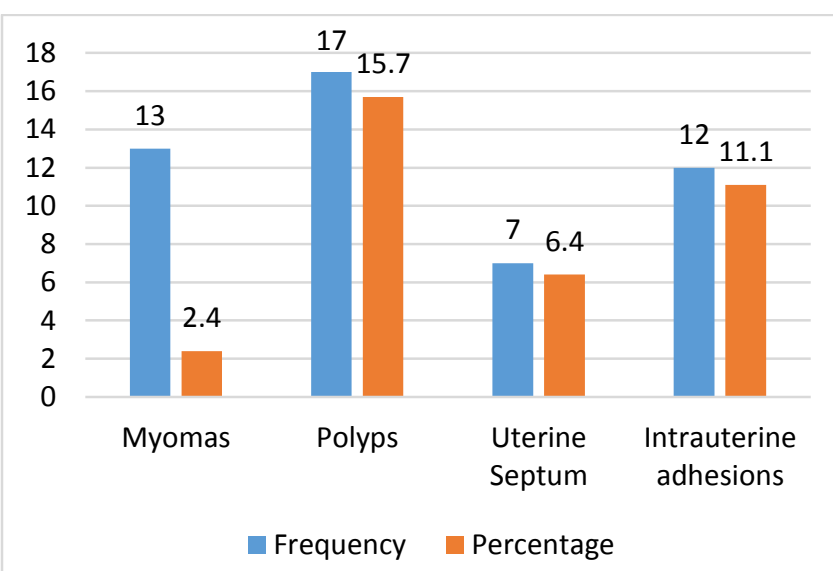

Figure 2. Prevalence of Intrauterine Lesions of positive findings among 49 patients 
Out of 108 patients, 49 (45.4\%) had positive findings of abnormal uterine lesions including myomas in 13 (12.3\%), polyps 17 (15.7\%), uterine septum 7 (6.4\%) and intrauterine adhesions 12 (11.1\%).For hysterosonography, specificity, sensitivity, negative predictive value (NPV), positive predictive value and overall accuracy were 94\%, $77 \%, 81 \%, 74 \%$, and $92 \%$ respectively. Intrauterine lesions diagnostic parameters are as shown in Table 2. Figure 2 and Table 3 demonstrates individual intrauterine lesions such as myomas, polyps, uterine spectrum, and intrauterine adhesion. No serious complications were found in our study.

\section{DISCUSSION}

The direct visualization ofuterine lesions or cavities could be the advantage offers by hysteroscopy overconventional modalities. In obstetrics and gynecology complex cases, diagnosticprocedures can be improved by threedimensional sonography which evaluatesdifficult scanning and diagnosis. Availing hysterosongraphy diagnostic techniquescan improve specificity and sensitivity [14]. However, the protrusion and submucousmyoma assessment in the uterine cavity cannot be accurately diagnosed with other modalities like 2D ultrasound. A uterine cavity in either case normal and collapsed form, Sonohysteroscopy are accepted and can improve the images [15]. Compared to 2D, 3D sonohysteroscopy, insofar as submucous can accurately determine the submucousmyomas protrusion and diameter of the uterine cavity which significantly influence the resection's completeness [16].

Although the various studies concludedcongenital anomalies diagnosis with 3D sonohysterography as accurate modalities[17] but others found no subsequent differences between 2D and 3Dsonohysterography [18].Many researchers found a satisfactory and accurate diagnosis of sonohysteroscopy in the diagnosis of various situations like infertility compared to conventional hysteroscopy [20]. Abnormal uterine bleeding, spontaneous recurrence miscarriage, and the present study investigated hysterosonography in women of reproductive ages. Another study's [21] results matched this investigation's findings. The author found higher specificity, sensitivity, NPV, PPV, and overall accuracy in hysterosonography compared to simple hysteroscopy. It has been reported that hysterosonography is an important technique for the evaluation of the uterine cavity with premenopausal bleeding. Additionally, 180 patients were investigatedin order to determine infertility among them by sonohysteroscopy and outpatienthysteroscopy fund comparable in detecting uterine lesions. Moreover, thesuggested that hysterosonography could be included in assessing women of normaluterine cavity with infertility [22]. Sonographic methods have the primary advantage of providing important extracavity information; adnexal masses and myometrial disorders, such as intramural myomas and adenomyosis, can be detected and explained [23].

Additionally, Sonohysteroscopy is comparatively economical, less time taker gives lower pain or discomfort to patients. However, a small size sample was the main limitation besides histopathology finding relation to study design and lack of correlation. Another study [24] carried out on 49 abnormal uterine bleeding women with prospective study design and randomized control trial technique to compare diagnostic accuracy, discomfort to the patient, and time taken for procedure completion between sonohysteroscopy and conventional hysteroscopy. Both were found comparable in the diagnosis of pain rating, procedure time, and intracavity lesions investigation. Hysterosonography or sonohysteroscopy was a more acceptable and comfortable imaging modality among patients.

\section{CONCLUSION}

The present study concluded that uterine lesions among reproductive-age women could be easily assessed with higher accuracy of hysterosonography. Based on the specificity and sensitivity of hysteroscopy as a gold standard for hysterosonography is the most reliable, safe and accurate diagnostic technique for uterine lesions.

\section{REFERENCES}

1. Yousuf $B$, Ambreen $H$, Mariam $T$, Raouf A, Yaseen A, Aslam $R$, Ahsan $M$. DIAGNOSTIC ACCURACY OF SALINE HYSTEROSONOGRAPHY IN DETECTING ENDOMETRIAL HYPERPLASIA IN PATIENTS WITH POST MENOPAUSAL BLEEDING. Journal of University Medical \& Dental College. 2020 Jul 10;11(2):1-8.

2. Kaveh M, Sadegi K, Salarzaei M, Parooei F. Comparison of diagnostic accuracy of saline infusion sonohysterography, transvaginal sonography, and hysteroscopy in evaluating the endometrial polyps in women with abnormal uterine bleeding: a systematic review and meta-analysis. Videosurgery and Other Miniinvasive Techniques. 2020 Sep;15(3):403.

3. Veleva Z. Uterine Cavity Assessment (Saline Hysterosonography). InUltrasound in Assisted Reproduction and Early Pregnancy 2020 Oct 22 (pp. 47-62). CRC Press.

4. Moradan S, Darzi SN, Ghorbani R. Diagnostic value of saline infusion sonohysterography for detecting endometrial focal lesion. The Pan African Medical Journal. 2019;33.

5. Mishra. B, Singh V, Sahu $M$ and Sinha $S$. Comparativestudyonsalineinfusion sonography vs. conventional ultrasound in evaluation of endometrial pathology, in patients with abnormal uterine bleeding. International Journal of Current Inovation Research.2018;4:996-1001.DOI: 10.24327/IJCIR.16.

6. Draz MH, El-Sabaa TM, El Shorbagy SH. Salineinfusionsonographyversus hysteroscopy in the evaluation of uterine cavityinwomenwithunexplained infertility.TantaMedicalJournal. 2017;45(3):155159.YOUSUF B., AMBREEN H., et al.SCSH IN ENDOMETRIAL HYPERPLASIA.

7. TangriMK,SrivastavaAK.Diagnostic accuracy of saline infusion sonography as comparedtohysteroscopyin premenopausalwomenwithabnormal uterine bleeding. International Journal of ReproductionContraception,Obstetrics and Gynecology. 2017;6(2):682-687. DOI: 10.18203/23201770.ijrcog20170405

8. Loiacono RM, Trojano G, Del Gaudio N, Kardhashi A, Deliso MA, Falco G, et al. Hysteroscopy as a valid tool for endometrial pathology in patients with postmenopausal bleeding or asymptomatic patients with a thickenedendometrium:hysteroscopic and histological results. Gynecologic and Obstetric Investigation. 2015;79(3):210-216.DOI:10.1159/000371758PMID: 25765014 . 
9. ZafarH,NazM,FatimaU.Diagnostic accuracy of saline sonohysterography for evaluation of uterine cavity abnormalities in patients with abnormal uterine bleeding. The Professional Medical Journal. 2019; 26(6):892895.DOI:10.29309/TPMJ/ 2019.26.05.3589.11.LuterekK

10. ,Szymusikl,BartkowiakR, Wielgos M. Sonohysterography in peri-and postmenopausalwomenwithabnormal uterine bleeding or abnormal endometrial appearance. Neuro Endocrinology letters. 2014;35(4): 297-300. PMID: 25038603.12.

11. Mwafy A. The diagnostic value of saline infusionsonohysterographyversus hysteroscopy in evaluation of uterine cavity in patients with infertility and recurrent pregnancy loss. Thai Journal of Obstetrics and Gynaecology. 2015:113-117.

12. Short J, Sharp B, Elliot N, et al. Does the addition of saline infusion sonohysterography to transvaginal ultrasonography prevent unnecessary hysteroscopy in premenopausal women with abnormal uterine bleeding? Aust $\mathrm{N}$ Zeal $\mathrm{J}$ ObstetGynaecol. 2016;56:432-5.

13. Inoue T, Kitajima M, Taniguchi K, Masuzaki H. Threedimensional saline-infusion sonohysterography is useful for the identification of endometrial polyp. J ObstetGynaecol Res. 2016;42:855-9.

14. Whitaker L, Critchley HO. Abnormal uterine bleeding. Best Pract Res ClinObstetGynaecol. 2016;34:54-65.

15. Bradley LD, Gueye NA. The medical management of abnormal uterine bleeding in reproductive-aged women. Am J Obstet Gynecol. 2016;214:31-44.

16. Shea AK. Comparison of saline infusion sonohysterography and transvaginal ultrasound in detection of endometrial polyps. EC Gynaecol. 2018;7:260-4.
17. Yang T, Pandya A, Marcal L, et al. Sonohysterography: principles, technique and role in diagnosis of endometrial pathology. World J Radiol. 2013;5:81-7.

18. Silva Wanderley M, Álvares MM, Vogt MD, Sazaki LM Accuracy of transvaginal ultrasonography, hysteroscopy and uterine curettage in evaluating endometrial pathologies. Rev Bras Ginecol Obstet. 2016;38:506-11.

19. Godoy Junior CE, Antunes Junior A, Morais SS, et al Accuracy of sonography and hysteroscopy in the diagnosis of premalignant and malignant polyps in postmenopausal women. Rev Bras Ginecol Obstet. 2013;35:243-8.

20. Ozer A, Ozer S, Kanat-Pektas M. Correlation between transvaginal ultrasound measured endometrial thickness and histopathological findings in Turkish women with abnormal uterine bleeding. J ObstetGynaecol Res. 2016;42:573-8.

21. Jokubkiene L, Sladkevicius $P$, Valentin L. Appearance of the endometrium at saline contrast sonohysterography in the luteal phase of the menstrual cycle: a prospective observational study. Ultrasound Obstet Gynecol. 2015;45:339-45.

22. Bhaduri M, Tomlinson G, Glanc P. Likelihood ratio of sonohysterographic findings for discriminating endometrial polyps from submucosal fibroids. J Ultrasound Med. 2014;33:149-54.

23. Moradan S, Darzi SN, Ghorbani R. Diagnostic value of saline infusion sonohysterography for detecting endometrial focal lesion. Pan Afr Med J. 2019;33:211.

24. Vathanan V, Armar NA. A comparative observational study of the use of saline uterine hydrosonography for the diagnosis and assessment of uterine cavity lesions in women. Int J Reproduct Med. 2016;2016:9317194. 